\title{
HEALTH PROMOTION BEHAVIOUR FOR NON-COMMUNICABLE DISEASES AMONG HEALTHCARE WORKERS IN KAKAMEGA COUNTY, KENYA
}

\author{
Micky Oloo Olutende ${ }^{1 i}$, \\ Maximilla N. Wanzala ${ }^{2}$, \\ Elizabeth Mse', \\ Edwin Kadima Wamukoya ${ }^{1}$ \\ ${ }^{1}$ Department of Health Promotion and Sports Science, \\ Masinde Muliro University of Science and Technology, \\ Kenya \\ 2Department of Public Health, \\ Masinde Muliro University of Science and Technology,
}

Kenya

\begin{abstract}
:
Introduction: The rising burden of non-communicable diseases poses a great health system challenge in Kenya. Healthcare workers have a critical role to play in health promotion, in addressing patients' lifestyle risk factors. However, their own lifestyle habits can influence their attitude and practices towards patient care. Opportunistic counselling of patients by health professionals signifies one of the most cost-effective medical interventions in combatting non-communicable diseases. Objective: To determine the attitudes and practice of health promotion for the prevention and management of non-communicable diseases among healthcare workers In Kakamega county. Methods: A cross-sectional mixed method study was carried out from June to July 2018 at Kakamega county referral hospital. For the quantitative method, one hundred and eighty-five doctors and nurses were recruited through stratified sampling. Data on healthcare workers; socio-demographic characteristics, lifestyle practice, attitude, and practice of health promotion was collected through self- administered questionnaires. Frequency and percentage distributions tables were used to initially describe the study population while, Chi- square test of significance was used to evaluate the association between healthcare workers attitudes and practice of health promotion and their socio-demographic features. Secondly, a total of 12 doctors and nurses were purposively selected based on age, gender and profession of participants for the qualitative method. Data on healthcare workers perspective on health promotion and organizational support factors were collected through in-depth interviews. The recorded
\end{abstract}

i Correspondence: email micky.oloo.mf@gmail.com 
interviews were transcribed and data analysis was done using content analysis of thematic areas. A verbatim approach was used to describe study findings. Results: $69.2 \%$ of the respondents were females, mean age was 36 years and the median years in profession was 12 years. The respondents exhibited good lifestyle practices with alcohol and tobacco prevalence at $30.8 \%$ and $3.8 \%$ respectively. $72 \%$ of the respondents demonstrated a positive attitude towards health promotion while, 31\% showed good health promotion practices. Less than half of the respondents inquired about a patient's lifestyle practices during routine visit. The study found that healthcare workers with a positive attitude were four times more likely to have good health promotion practices $(\mathrm{OR}=3.54, \mathrm{p}<0.001)$. Lastly findings from the in-depth interviews revealed that staff had no written guidelines on health promotion and that the hospital management had abolished the health promotion unit. Conclusion: The results indicated that a positive health professional attitude is a precursor to good health promotive practices. Recommendation: Efforts to build capacity and support for health promotion in health services should be encouraged. Additionally, health Promotion programs for noncommunicable disease should not only target the health of general population but also the health of health care workers.

Keywords: practices, attitudes, Kakamega county, Kenya, risk factors, prevalence, noncommunicable diseases, diabetes

\section{Introduction}

The global health disease profile is rapidly evolving with deaths and disabilities from non-communicable diseases (NCDs) surpassing those from infectious diseases, resulting in a double burden of diseases (WHO, 2013a). It is estimated that about $80 \%$ of cardiovascular diseases and type 2 diabetes could be prevented through adoption and maintenance of healthier lifestyle practices, such as, tobacco cessation, healthy dietary habits, and reduction in alcohol consumption (Holmberg et al., 2014). Therefore, healthcare settings offer an ideal entry point for health promotion, as $80 \%$ of the general population visits a hospital one or more times each year (Spanou et al., 2010). In addition, healthcare workers are deemed to be trustworthy thus are at a vantage point to provide lifestyle counselling opportunistically to both at risk patients and the general population (Brotons et al., 2005; Johansson, Stenlund, Lundström, \& Weinehall, 2010). Noncommunicable diseases (NCDs) account for $60 \%$ of global deaths, with cardiovascular disease, cancers, chronic respiratory disease and diabetes constituting approximately $80 \%$ of all NCD-attributable deaths. (WHO, 2014a). In Kenya, NCDS account for $28 \%$ of the total deaths, the leading causes of NCD mortality are; cardiovascular disease $(8 \%$ of total mortality), cancers (7\%), chronic respiratory disease $(1 \%)$ and diabetes $(2 \%)$ (WHO, 2014b). The burden of NCDs has been linked to exposure to four modifiable lifestyle risk factors; these are tobacco use, alcohol consumption, unhealthy diet and physical inactivity. It has been stated that $80 \%$ of cardiovascular disease, $90 \%$ of type 2 diabetes, 
and $30 \%$ of all cancers are preventable if the four lifestyle risk factors were reduced or eliminated (WHO, 2014a). Therefore, preventive strategies which will ensure primary prevention of NCDs as well as minimizing the consequences of the disease are of great importance.

The rising trends in NCDs have been shown to exert constraints on individuals, household and communities by heightening poverty and increasing health inequities, consequently putting at risk the gains of social and economic development (Robinson \& Hort, 2012). In addition, a retrospective study on the public health implications of diabetes in low- and middle-income countries showed that the double burden of diseases imposes an enormous strain on the existing healthcare system, as both conditions compete for limited finances and political attention (Hall, Thomsen, Henriksen, \& Lohse, 2011). Despite the devastating social, economic and public health impact of NCDS, studies have shown them to be preventable (Aikins et al., 2010; Robinson \& Hort, 2012; WHO, 2014a). For prevention of NCDs to be most effective, focus must be on activities that encourage healthy living and limit the initial onset of NCDs. Prevention should also embrace early detection efforts, such as screening at-risk populations, as well as strategies for appropriate management of existing diseases and related complications (WHO, 2013a). To achieve this, there is a need for adoption of holistic interventions to address NCDs, through raising awareness and empowering people to take charge of their health and well- being. This captures the essence of health promotion, whose aim is enabling people to take control over their health (Dobe, 2012).

There has been an increasing recognition that curative interventions alone cannot guarantee better health considering, health is greatly influenced by factors outside the scope of the health sector, such as social, political and economic factors. These factors impact the way in which people live, work, and age (Coe \& Beyer, 2014; Kumar \& Preetha, 2012). Thus, the attainment of the highest possible standard of health depends on a holistic approach involving communities, health providers and the population at large (Kemppainen, Tossavainen, \& Turunen, 2013). Therefore, to reduce and halt the rise of NCDs, it is essential to have a coordinated, and holistic prevention approach that promotes healthy behaviours, expands early detection and diagnosis of disease, and eliminates health disparities (Dobe, 2012; Kumar \& Preetha, 2012).

Lifestyle practices characterize modifiable behaviour that affect either positively or negatively, the health of an individual. The lifestyle one adopts is based on a multitude of causes, from childhood determinants, to personal history, to influences in the cultural, physical, economic, and political environments (Sharma, Anand, Kishore, Dey, \& Ingle, 2014). Thus, in this section, the focus will be on lifestyle practices which impact on NCDs, these include: Smoking, alcohol consumption, diet and physical activity. Healthcare workers have, in numerous studies, been shown to report healthier lifestyles than the general population (Frank et al., 2013; Frank \& Segura, 2009; Klein, Guenther, \& Ross, 2016) however, not all studies correspond with this notion, some studies show that HCWs don't consistently report healthier lifestyle with regard to smoking, physical activity, and dietary habits, when compared to other individuals (Jonsdottir et al., 2011). A South 
African study on obesity among HCWs indicated $75 \%$ of the study population was overweight, obese or severely obese (Skaal \& Pengpid, 2011). Another study on alcohol use among healthcare workers, showed that a significant proportion of HCWs have high rates of alcohol use, with increase of consumption over time (Bakhshi \& While, 2014). A study done in Kenya on lifestyle related risk factors showed 78\% of the doctors surveyed consumed alcohol frequently while only $17 \%$ engaged in moderate or physical activity (Omar, 2007). NCDs among HCWs has been attributed to; higher disposable incomes, and adoption of western culture and lifestyle (Skaal \& Pengpid, 2011). Thus, successful interventions to encourage healthier lifestyle behaviours', including physical activity and diet, among HCWs, is of great importance, as HCWs serve as precursors of how the general population perceive harmful lifestyle practices (Tyzuk, 2012).

Healthcare workers play a central role in health promotion and behaviour modification towards patients. It has been shown that a majority of people would most likely adopt healthy lifestyles when recommended by a HCW than any other profession (Oberg \& Frank, 2009). A cross-sectional study on smoking cessation practices among healthcare workers in Kenya indicated that $97 \%$ of the HCWs believed that it was their responsibility to assist and motivate patients, however, only 35\% provided smoking cessation interventions (Gichuki, 2014). This observation is evident in numerous studies where despite overwhelming consensus on the importance of lifestyle behaviour counselling to patient, very few HCWs apply the principles of HP in their daily practice (Laws et al., 2009; Paz \& Luquis, 2014; Stead et al., 2009). Research indicates that for successful implementation of health promotion within health services, the health promotion goals need to be more compatible with the HCW's own values, norms and perceived needs (Johansson et al., 2010). For instance, the HCWs' attitudes and practice to HP has been found to be influenced by their belief and confidence in their own effectiveness in ultimately promoting lifestyle behavioural change in patient. For instance, doctors who viewed HP as not part of their responsibility did not engage in it or may suggest the role to be taken on by other health professionals (Laws et al., 2009).

The concept of health promotion in health services was introduced more than 20 years ago with an aim to reorient health services to adopt health promotion activities (McHugh, Robinson, \& Chesters, 2010). Evidence suggests that brief lifestyle interventions delivered within healthcare facilities are highly effective (Harris, 2008; Laws et al., 2008; Spanou et al., 2010). Health promotion significantly relies on mediation and advocacy through, creating an enabling environment for people, individually and collectively, to increase control over their health and its determinants. These enabling environments are vital for the prevention and control of NCDs (Dobe, 2012). Healthcare facilities offer an ideal setting for health promotion, as about $80 \%$ of the general population visits a hospital one or more times each year (Jonsdottir, Börjesson, \& Ahlborg, 2011). Therefore, healthcare workers (HCWs) are at a vantage point to provide health promotion counselling opportunistically, that is, when patients visit them for any reason (Spanou et al., 2010). 


\section{Methods}

A cross-sectional study was conducted to describe and explore the perspective of healthcare workers attitudes and practice of health promotion for non-communicable diseases at Kakamega county referral hospital. The study employed both qualitative and quantitative methods.

\subsection{Subjects/groups}

The target population for this study were healthcare workers from two health cadres, namely doctors, and nurses. The desired sample size was calculated using the Fisher's statistical formula (Daniel 2009) for determining sample size for a cross-sectional study. Stratified sampling procedure was used to enlist participants for the study. This was done to avoid bias in the selection process by ensuring that the study participants are equally represented from the medical and reproductive health departments respectively. Healthcare workers were stratified per their representative department. Proportionate allocation based on number of HCWs in each unit of their respective department was used to determine the number of HCWs to be sampled from each department. Healthcare workers from each stratum were then selected using simple random sampling technique. For the qualitative aspect of the study, the study participants were selected purposively based on their age, gender and cadre. The sampling of respondents for interviews were stopped when theoretical saturation of a given concept is achieved (Sargeant, 2012). A total of 12 respondents were approached to be interviewed. Participants were excluded if; Healthcare workers not within the two cadres or if the healthcare workers not involved in providing patient care, that is, are in administrative positions.

\subsection{Measures}

\subsubsection{Quantitative data collection}

Data was collected for two months, from 1st June to 29th July 2018, through selfadministered questionnaires which were distributed to the study respondents at their respective ward/ units. Different distribution strategies were used, in order to increase the likelihood of participation. Selected participants were approached for recruitment by the principal investigator at their respective wards/ units after obtaining verbal clearance from the in charges. In some wards/units the in-charges were responsible for the distribution of the questionnaires to the selected participants in their respective ward/unit department. The questionnaires were collected from the respondents at their work station at a time convenient to them or were left with the in- charges of each ward/unit.

\subsubsection{Qualitative data collection}

Data was collected through in-depth interviews. Selected participants were briefed on the study and consent forms were provided to the respondents before carrying out the interview. Upon receipt of the signed consent, the in-depth interview was conducted on 
the selected health care workers using an open-ended interview guide. The sessions were conducted privately at a time convenient with the respondent and were audio-recorded, except on two occasions where the respondents declined to be voice recorded, thus comprehensive notes were written down to obtain the information. The interviews were conducted in English and lasted between 15- 30 minutes.

\subsubsection{Data management}

At the end of each day during the data collection period, questionnaires were checked for completeness, clarity and consistency. In addition, each verified questionnaire was sequentially coded according to date of collection for ease of storage and to ensure anonymity. Qualitative data was transcribed on MS Word document, and the audio recordings were downloaded and stored online on a computer folder.

\subsection{Statistical analysis}

To provide an initial description of the study population, the data was tabulated using frequency and percent distributions for the predictor variables; this included sociodemographic characteristics and behavioral practices. To determine the general attitude towards health promotion, points were awarded for the responses where a strong agreement with a positively worded constructs awarded a weight of 5 points while strong disagreement with a positively worded constructs awarded 1 point. These scores were then summed up and graded such that a score less than or equal to 10 points were deemed to be negative attitude, scores between 11 and 20 were deemed neutral, while scores more than 21 were deemed positive attitude. Subsequently, Pearson's Chi- square ( $\chi 2)$ test was used to establish a statistical significance between a HCWs attitudes to health promotion and their socio- demographic characteristics.

To determine the level of practice to health promotion, scores were awarded to the activities performed by HCWs to engage and motivate patients to take up healthy lifestyles. This was done such that, healthcare workers who inquired about lifestyle practices every time they saw a patient were awarded 3 points, HCWs who inquired about lifestyle practices on patients who were 'at risk' were awarded 2 points, HCWs who inquired about lifestyle practices from patients with chronic illness were awarded 1 point while health workers who never sought information from patients were not awarded any point. These resultant points were then summed up for information on tobacco use, alcohol consumption, dietary habits and physical activity. The sum was then ranked such that health workers scoring 4 points and below were deemed to have poor health promotion practices, health workers scoring between 5 and 7 points were deemed to have average health promotion practices while health workers scoring more than 8 points were deemed to have good health promotion practices. Subsequently, Pearson's Chi- square $(\chi 2)$ test was used to establish a statistical significance between a HCWs practice of health promotion and their socio-demographic characteristics, in addition, chi- square was used to establish statistical significance between NCD competency of healthcare workers and their frequency of inquiry of lifestyle risk factors to their patients 
the HCW competency. The level of significance was set at 95\%. Lastly, to establish if a healthcare worker's attitude was associated with their practice of health promotion, bivariate analysis was carried using SPSS version 25. For qualitative data analysis, the audio- recorded interviews were transcribed by the principal investigator onto a Microsoft word document. Coding was done manually to identify running themes. Texts that were indicators of themes corresponding to the research objectives were highlighted within the coded transcripts. A narrative approach was used to describe the findings of the study so as to better elaborate the views and experiences of the healthcare workers.

\section{Results}

The study targeted 185 healthcare workers however, the number of questionnaires returned were 166. Of the returned questionnaires, 10 were incomplete hence were excluded from the study resulting in 156 completed questionnaires, yielding a response rate of $84.3 \%$. Of the 156 respondents, the majority were female 108 (69.2\%) thus, giving a male to female ratio of 2:3. Three out of five respondents were married at the time of the research. The respondents' age ranged from 25 to 60 years (median age 36). The least experienced respondent had practiced for only one year while the most experienced one for 35 years thus the median number of years in practice was 12 (Table 1).

Table 1: Socio-demographic characteristics of study participants

\begin{tabular}{|c|c|c|c|c|c|c|}
\hline \multirow{3}{*}{ Variable } & \multicolumn{6}{|c|}{ Profession } \\
\hline & \multicolumn{2}{|c|}{$\begin{array}{l}\text { Medical officer } \\
\quad(n=20)\end{array}$} & \multicolumn{2}{|c|}{$\begin{array}{c}\text { Nurse } \\
(n=136)\end{array}$} & \multicolumn{2}{|c|}{$\begin{array}{c}\text { Total } \\
(n=156)\end{array}$} \\
\hline & \multicolumn{2}{|c|}{$\mathrm{F}^{*}$} & \multicolumn{2}{|r|}{$F$} & \multicolumn{2}{|c|}{$F$} \\
\hline \multicolumn{7}{|l|}{ Gender } \\
\hline Female & 13 & 65 & 95 & 69.9 & 108 & 69.2 \\
\hline Male & 7 & 35 & 41 & 30.1 & 48 & 30.8 \\
\hline \multicolumn{7}{|l|}{ Marital Status } \\
\hline Not yet married & 11 & 55 & 43 & 31.6 & 54 & 34.6 \\
\hline Currently married & 9 & 45 & 85 & 62.5 & 94 & 60.3 \\
\hline Separated/divorce & 0 & 0 & 4 & 2.9 & 4 & 2.6 \\
\hline Widowed & 0 & 0 & 4 & 2.9 & 4 & 2.6 \\
\hline \multicolumn{7}{|l|}{ Age in years } \\
\hline$<=25$ & 0 & 0 & 3 & 2.2 & 3 & 1.9 \\
\hline $26-35$ & 16 & 80 & 71 & 52.2 & 87 & 55.8 \\
\hline $36-45$ & 3 & 15 & 37 & 27.2 & 40 & 25.6 \\
\hline $46-55$ & 1 & 5 & 21 & 15.4 & 22 & 14.1 \\
\hline$>55$ & 0 & 0 & 4 & 2.9 & 4 & 2.6 \\
\hline \multicolumn{7}{|l|}{ Years of experience } \\
\hline$<=3$ & 5 & 25 & 17 & 12.5 & 22 & 14.1 \\
\hline $4-7$ & 8 & 40 & 40 & 29.4 & 48 & 30.8 \\
\hline $8-10$ & 5 & 25 & 15 & 11 & 20 & 12.8 \\
\hline$>10$ & 2 & 10 & 64 & 47.1 & 66 & 42.3 \\
\hline
\end{tabular}

${ }^{*} \mathrm{~F}=$ Frequency, $\%=$ percentages 


\subsection{Healthcare Workers' Lifestyle Practices}

To assess the smoking practices among the respondents, the study found a majority (91\%) had never smoked at the time of the research (Table 2). Of those who were currently smoking 2(33.3\%) smoked daily, 2(33.3\%) smoked 2-3 times a week and 2(33.3\%) smoked rarely. Only $1(16.6 \%)$ of current smokers had tried to quit smoking during the past 12 months. Of the respondents who were non-smokers, inclusive of ex-smokers, a majority $101(67.3 \%)$ of them had been exposed to secondary smoke within the past 30 days.

Table 2: Tobacco use among respondents

\begin{tabular}{|l|c|c|c|c|c|c|}
\hline $\mathbf{n}=\mathbf{1 5 6}$ & \multicolumn{2}{|c|}{ Medical officer } & \multicolumn{2}{|c|}{ Nurse } & \multicolumn{2}{c|}{ Total } \\
\hline Smoking experience & $\mathbf{F}$ & $\mathbf{\%}$ & $\mathbf{F}$ & $\mathbf{\%}$ & $\mathbf{F}$ & $\mathbf{\%}$ \\
\hline Current smoker & 0 & 0 & 6 & 4.4 & 6 & 3.8 \\
\hline Ex-smoker & 2 & 10 & 6 & 4.4 & 8 & 5.1 \\
\hline Never smoked & 18 & 90 & 124 & 91.2 & 142 & 91.0 \\
\hline
\end{tabular}

An assessment of alcohol consumption revealed that slightly over a half of the respondents, $85(54.5 \%)$ had never consumed alcohol while 48(30.8\%) consumed alcohol at the time of the research. Over half, of those who were currently consuming alcohol $42(59.2 \%)$ consumed it occasionally and took an average of 3 bottles on this occasion. However, only $3(4.2 \%)$ of the current alcohol consumers felt like they needed a drink in the morning to get themselves going for the day (Table 3).

Table 3: Alcohol consumption among study participants

\begin{tabular}{|l|c|c|c|c|c|c|}
\hline \multirow{2}{*}{ Variable } & \multicolumn{7}{|c|}{ Profession } \\
\cline { 2 - 7 } & \multicolumn{2}{|c|}{ Medical officer } & \multicolumn{2}{c|}{ Nurse } & \multicolumn{2}{c|}{ Total n=156 } \\
\cline { 2 - 7 } & $\mathbf{F}$ & $\mathbf{\%}$ & $\mathbf{F}$ & $\mathbf{\%}$ & $\mathbf{F}$ & $\mathbf{\%}$ \\
\hline Alcohol consumption & 7 & 35.0 & 41 & 30.1 & 48 & 30.8 \\
\hline Currently consuming & 2 & 10.0 & 21 & 15.4 & 23 & 14.7 \\
\hline Quit consuming & 1 & 55.0 & 74 & 54.4 & 85 & 54.5 \\
\hline Never consumed & \multicolumn{7}{|c|}{} \\
\hline Frequency of having at least one standard alcoholic drink during the past 12 months \\
\hline Daily & 2 & 22.2 & 9 & 14.5 & 11 & 15.5 \\
\hline Weekly & 0 & 0.0 & 7 & 11.3 & 7 & 9.9 \\
\hline $1-3$ times a month & 3 & 33.3 & 8 & 12.9 & 11 & 15.5 \\
\hline Occasionally & 4 & 44.4 & 38 & 61.3 & 42 & 59.2 \\
\hline
\end{tabular}

The study sought to reveal the dietary habit of study participants through an assessment of their fruit and vegetable intake, dietary salt intake and meals not prepared at home. Study participants were queried on their fruit and vegetable consumption in a typical week. The study showed on average the participants took fruits 4 times a week composing averagely of 3 servings, where one serving consists of one whole fruit, or $1 / 4$ cup of fruit juice. With regards to vegetable consumption, they averagely took vegetables five times a week in 4 servings, where one serving consists of 3 tablespoons of cooked vegetables (Table 4 ). 
Table 4: Average number of fruits and vegetables consumed by study participants

\begin{tabular}{|l|c|}
\hline Variables & Average number $(\mathbf{n}=\mathbf{1 5 6})$ \\
\hline No. of times fruits taken in a week & 4 \\
\hline No. of times vegetables taken in a week & 5 \\
\hline Serving of fruit & 3 \\
\hline Serving of vegetables & 4 \\
\hline
\end{tabular}

A look at the salt intake and consumptions of meal not prepared at home by study respondents showed that, $27.5 \%$ of respondents' always and often added salt to their food while, $11.5 \%$ often ate processed food high in salt. Over half of the medical officers ate on a daily or almost daily basis meals that were not prepared at home compared to only slightly less than a third of nurses who ate meals not prepared at home (Table 5).

Table 5: Dietary salt intake and consumption of meals not prepared at home by study respondents

\begin{tabular}{|c|c|c|c|c|c|c|}
\hline \multirow{3}{*}{ Categories } & \multicolumn{6}{|c|}{ Profession } \\
\hline & \multicolumn{2}{|c|}{ Medical officer } & \multicolumn{2}{|c|}{ Nurse } & \multicolumn{2}{|c|}{ Total } \\
\hline & $F$ & $\%$ & $\mathbf{F}$ & $\%$ & $\mathbf{F}$ & $\%$ \\
\hline \multicolumn{7}{|c|}{ Add salt or a salty sauce to food right before eating or during eating } \\
\hline Always & 1 & 5 & 17 & 12.5 & 18 & 11.5 \\
\hline Often & 10 & 50 & 15 & 11.0 & 25 & 16.0 \\
\hline Sometimes & 6 & 30 & 46 & 33.8 & 52 & 33.3 \\
\hline Rarely & 2 & 10 & 33 & 24.3 & 35 & 22.4 \\
\hline Never & 1 & 5 & 25 & 18.4 & 26 & 16.7 \\
\hline \multicolumn{7}{|c|}{ Eat processed food high in salt } \\
\hline Always & 0 & 0 & 4 & 2.9 & 4 & 2.6 \\
\hline Often & 6 & 30 & 12 & 8.8 & 18 & 11.5 \\
\hline Sometimes & 12 & 60 & 44 & 32.4 & 56 & 35.9 \\
\hline Rarely & 2 & 10 & 60 & 44.1 & 62 & 39.7 \\
\hline Never & 0 & 0 & 16 & 11.8 & 16 & 10.3 \\
\hline \multicolumn{7}{|c|}{ Consumption of meals not prepared at a home } \\
\hline Daily or almost daily & 11 & 55 & 37 & 27.2 & 48 & 30.8 \\
\hline Weekly & 8 & 40 & 26 & 19.1 & 34 & 21.8 \\
\hline Monthly & 0 & 0 & 33 & 24.3 & 33 & 21.2 \\
\hline Less than a month & 1 & 5 & 35 & 25.7 & 36 & 23.1 \\
\hline Never & 0 & 0 & 5 & 3.7 & 5 & 3.2 \\
\hline
\end{tabular}

An assessment of the physical activities among the study respondents showed that slightly over half, (56\%) of the respondents stated that their work involved mostly sitting or standing with walking for no more than 10 minutes at a time. In addition, 87(55.8\%) participated in some form of physical activity during the past 30 days. The most common form of physical activity undertaken included; brisk walking, 61(66.3\%) while the least common physical activity was aerobics, 10(10.9\%). On average, the respondents took 44 minutes to exercise the physical activity of their choice (Table 6). 
Table 6: Physical activity among study participants

\begin{tabular}{|l|c|c|c|c|c|c|}
\hline Variable & \multicolumn{2}{|c|}{ Medical officers } & \multicolumn{2}{c|}{ Nurse } & \multicolumn{2}{c|}{ Total } \\
\hline & F & \% & F & \% & F & \% \\
\hline Work mostly involve sitting or standing & 11 & 55.0 & 77 & 56.6 & 88 & 56.4 \\
\hline Yes & 9 & 45.0 & 59 & 43.4 & 68 & 43.6 \\
\hline No & 9 & 55.0 & 76 & 55.9 & 87 & 55.8 \\
\hline Participate in any form of Physical activity \\
\hline Yes & 11 & 45.0 & 60 & 44.1 & 69 & 44.2 \\
\hline No & 9 & \multicolumn{5}{|l|}{} \\
\hline Common form of physical activity undertaken & 7 & 63.6 & 54 & 66.7 & 61 & 66.3 \\
\hline Brisk walking & 5 & 45.5 & 20 & 24.7 & 25 & 27.2 \\
\hline Running & 5 & 18.2 & 8 & 9.9 & 10 & 10.9 \\
\hline Aerobics & 2 & 0.0 & 13 & 16.0 & 13 & 14.1 \\
\hline Gym sessions & 0 & \multicolumn{5}{|l|}{} \\
\hline
\end{tabular}

In addition, the study sought to reveal the self-perception about body weight among the study respondents. The study revealed, a majority $110(70.5 \%)$ of the respondents considered their weight to be normal while, 40(25.7\%) considered their weight as either obese or overweight (Table 7).

Table 7: Weight perceptions among study respondents

\begin{tabular}{|l|c|c|c|c|c|c|}
\hline \multirow{2}{*}{ Variable } & \multicolumn{9}{|c|}{ Profession } \\
\cline { 2 - 7 } & \multicolumn{2}{|c|}{ Medical officer } & \multicolumn{2}{c|}{ Nurse } & \multicolumn{2}{c|}{ Total } \\
\hline & F & \% & F & \% & F & \% \\
\hline Underweight & 1 & 5 & 5 & 3.7 & 6 & 3.8 \\
\hline Normal weight & 14 & 70 & 96 & 70.6 & 110 & 70.5 \\
\hline Overweight & 5 & 25 & 31 & 22.8 & 36 & 23.1 \\
\hline Obese & 0 & 0 & 4 & 2.9 & 4 & 2.6 \\
\hline
\end{tabular}

The study sought to identify the diseases and health conditions currently affecting healthcare workers through self-reporting by the respondents in addition, frequency of going for medical check-up was assessed. The findings revealed that, three fifths of the respondents reported that they were not hypertensive $(62.2 \%)$ or diabetic $(61.5 \%)$. However, slightly over half of the respondents have never tested for cancer $(57.1 \%)$, also less than half (46.2) did not test for heart diseases (Figure 1). 
Figure 1: Self-reported non-communicable disease profile among study participants

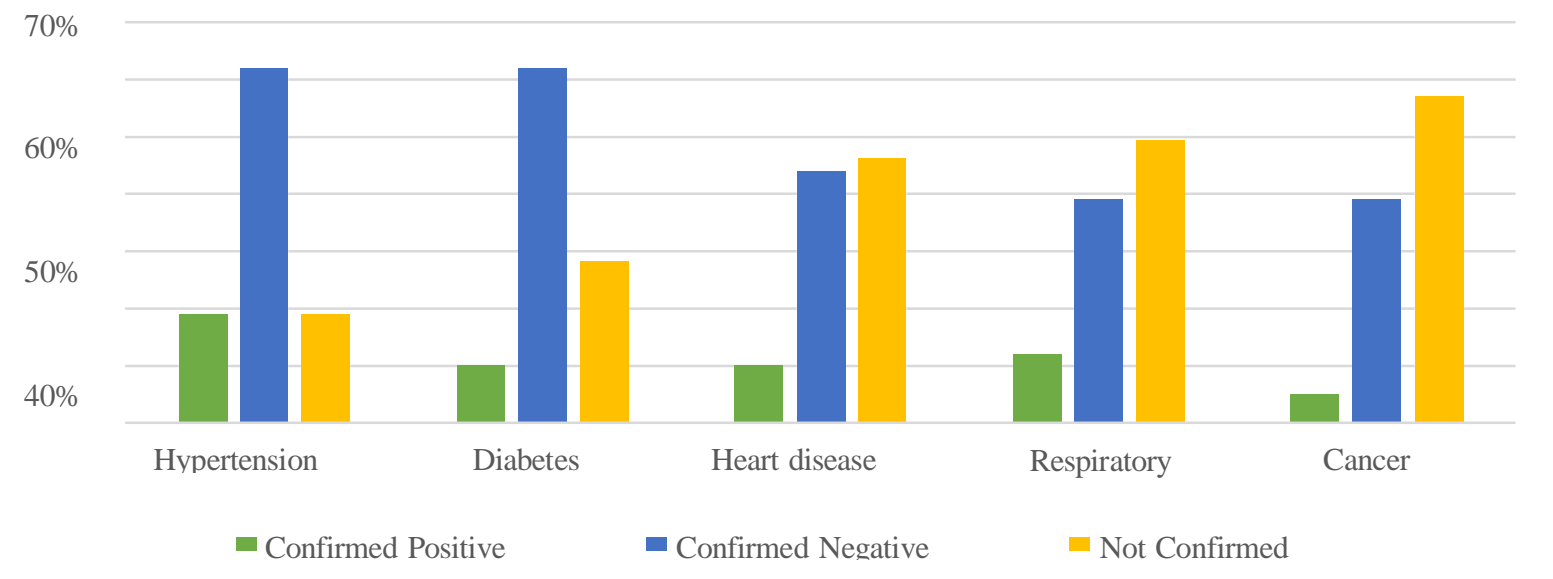

Seventy-three $(46.8 \%)$ of the respondents were going for check-ups. Among these respondents nearly half $36(49.3 \%)$ were annually attending medical check-ups while slightly over a quarter 20(27.4\%) were attending medical check-ups every 2 to 3 years (Figure 2).

Figure 2: Self-reported health check-up rates among study participants

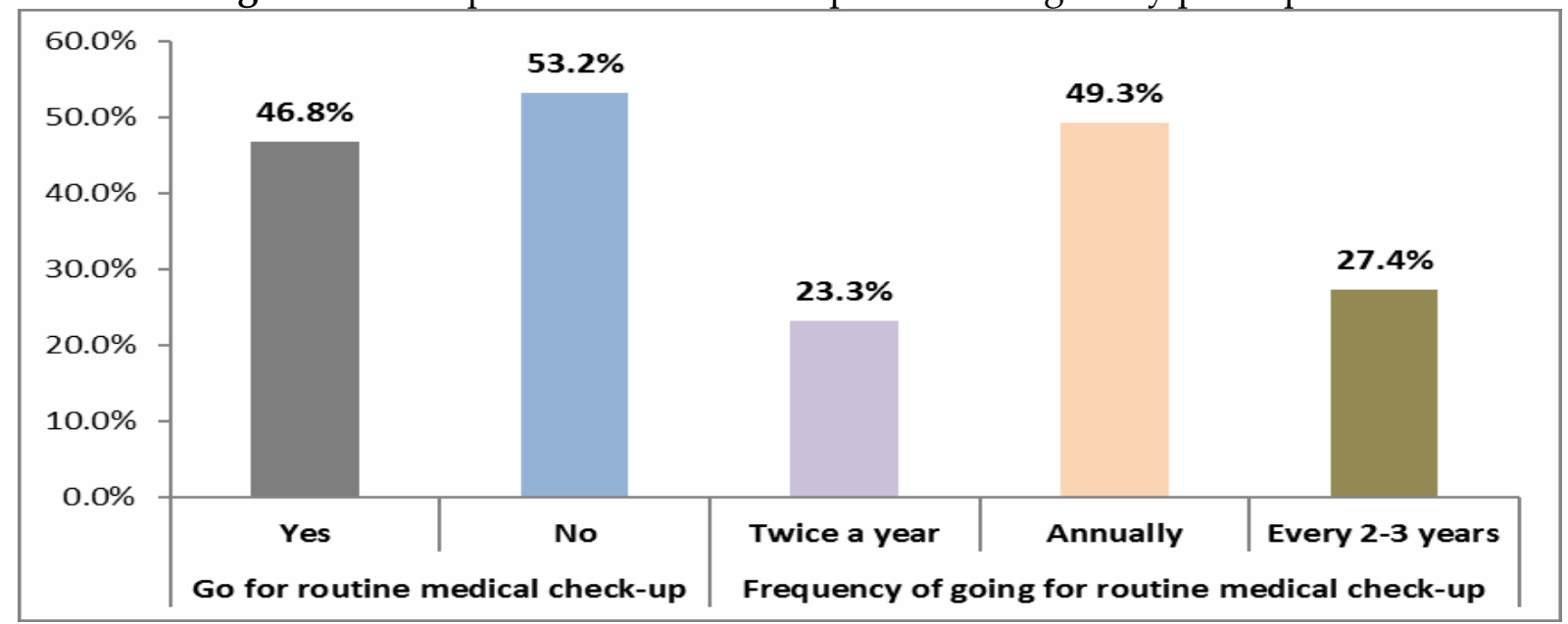

The interviews revealed that health care workers seldom went for the medical check- ups despite it being available and provided for by the hospital. One of the responses is shown below;

"We are actually encouraged by Kenyatta to have a medical check-up every year and it's free but what do we do? We are supported because medical care is free. If I go for exercises it's free here in Kenyatta in our physiotherapy department, it is free. The only thing they don't pay is gym. Do you know we are entitled to do a pap smear? But us (staff)... the fear! Even Pap smear people don't go. We are diagnosed when you are in third stage." (HCW 5) 


\subsection{Healthcare workers' attitudes to health promotion for NCDS}

The general attitude of healthcare workers on health promotion was assessed. Over half $(57.1 \%)$ of the respondents strongly agreed that it was a part of their daily practice to offer lifestyle counselling to their patients. However, a third (33.3\%) of the respondents agreed that they did not have sufficient time to do so. Furthermore, $65(41.7 \%)$ of the respondents strongly agreed that discussing healthy lifestyle behaviour with their patients was very rewarding for them. Finally, a majority of the respondents $(78.8 \%)$, indicated that all health workers were responsible for providing health promotion information to patients (Figure 3).

Figure 3: Healthcare workers' attitude to health promotion

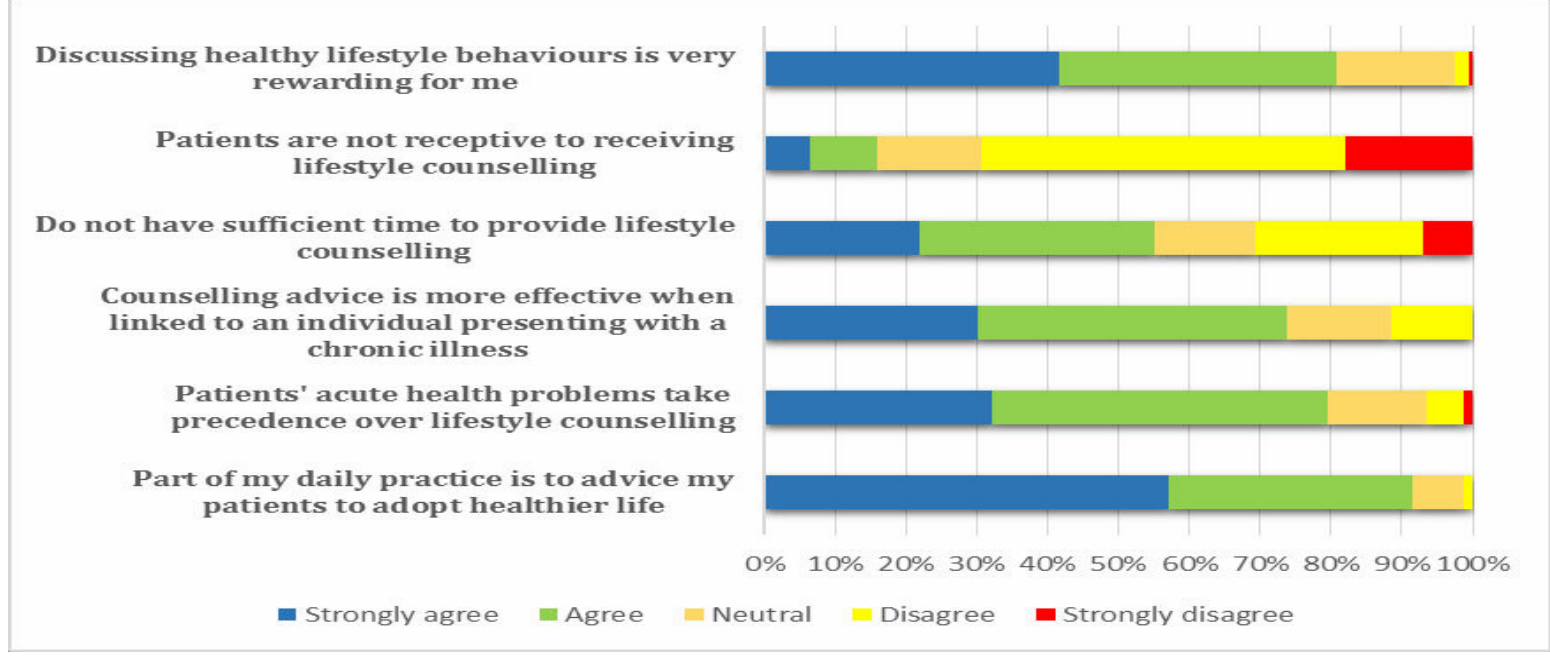

In order to provide an overview of the attitude of healthcare workers to health promotion, scores were provided. The results indicated that majority $113(72.4 \%)$ of the health workers had positive attitude while $43(27.6 \%)$ had neutral attitude and none had negative attitude towards health promotion.

\subsection{Relationship between attitudes to health promotion and socio-demographic characteristics}

To determine the association between various sociodemographic characteristics and the respondents' attitudes to health promotion, bivariate analysis was carried out. The results revealed that the respondents' gender, profession, marital status, age and years of experience were not statistically significant (Table 8). 
AMONG HEALTHCARE WORKERS IN KAKAMEGA COUNTY, KENYA

Table 8: Relationship between attitudes to health promotion and socio- demographic factors

\begin{tabular}{|c|c|c|c|c|}
\hline \multirow[b]{2}{*}{ Predictor variables } & \multicolumn{2}{|c|}{ Health promotion attitude } & \multirow[b]{2}{*}{$\begin{array}{l}\text { Chi-square } \\
\text { Test }\left(\chi^{2}\right)\end{array}$} & \multirow{2}{*}{$\begin{array}{c}\text { P- } \\
\text { Value }\end{array}$} \\
\hline & $\begin{array}{c}\text { Neutral } \\
\text { n (\%) }\end{array}$ & $\begin{array}{c}\text { Positive } \\
\text { n (\%) }\end{array}$ & & \\
\hline \multicolumn{3}{|l|}{ Gender } & \multirow{3}{*}{3.662} & \multirow{3}{*}{0.074} \\
\hline Female & $30(27.8)$ & $78(72.2)$ & & \\
\hline Male & $13(27.1)$ & $35(72.9)$ & & \\
\hline \multicolumn{3}{|l|}{ Profession } & \multirow{3}{*}{0.461} & \multirow{3}{*}{0.622} \\
\hline Medical officer & $5(25)$ & $15(75)$ & & \\
\hline Nurse & $38(27.9)$ & $98(72.1)$ & & \\
\hline \multicolumn{3}{|l|}{ Marital Status } & \multirow{4}{*}{0.667} & \multirow{4}{*}{0.982} \\
\hline Not yet married & $15(27.8)$ & $39(72.2)$ & & \\
\hline Currently married & $24(25.5)$ & $70(74.5)$ & & \\
\hline Separated/divorced/widowed & $4(50)$ & $4(50)$ & & \\
\hline \multicolumn{3}{|l|}{ Age categories } & \multirow{5}{*}{5.040} & \multirow{5}{*}{0.261} \\
\hline$<=35$ & $23(25.6)$ & $67(74.4)$ & & \\
\hline $36-45$ & $14(35)$ & $26(65)$ & & \\
\hline $46-55$ & $5(22.7)$ & $17(77.3)$ & & \\
\hline$>55$ & $1(25)$ & $3(75)$ & & \\
\hline \multicolumn{3}{|l|}{ Years of experience } & \multirow{5}{*}{2.887} & \multirow{5}{*}{0.411} \\
\hline$<=3$ & $5(22.7)$ & $17(77.3)$ & & \\
\hline $4-7$ & $9(18.8)$ & $39(81.3)$ & & \\
\hline $8-10$ & $8(40)$ & $12(60)$ & & \\
\hline$>10$ & $21(31.8)$ & $45(68.2)$ & & \\
\hline
\end{tabular}

\subsection{Healthcare workers' Practice of Health Promotion}

The study assessed the healthcare workers approach to ask and assess a patient's health practices, as well as how they assist their patients adopt healthy lifestyles, in addition to arranging follow up for at risk patients. In an effort to assess practice the study found that $68(43.6 \%)$ of the respondents inquired about tobacco use and 70(44.9\%) inquired about alcohol consumption, every time they saw a patient. However, $27(17.3 \%)$ of the health workers never inquired about patient's physical activity. (Table 9).

Table 9: HCWs response on inquiring about a patient's lifestyle behaviour

\begin{tabular}{|l|c|c|c|c|}
\hline $\begin{array}{l}\text { Variable } \\
\mathbf{n = 1 5 6}\end{array}$ & $\begin{array}{c}\text { To patients } \\
\text { Every time } \\
\mathbf{n}(\mathbf{\%})\end{array}$ & $\begin{array}{c}\text { To patients } \\
\text { who I see } \\
\text { 'are at risk' } \\
\mathbf{n} \mathbf{( \% )}\end{array}$ & $\begin{array}{c}\text { If the patient } \\
\text { presents with a } \\
\text { chronic illness } \\
\mathbf{n}(\mathbf{\%})\end{array}$ & Never \\
\hline Tobacco use & $68(43.6)$ & $64(41.0)$ & $19(12.2)$ & $5(3.2)$ \\
\hline Alcohol Consumption & $70(44.9)$ & $54(34.6)$ & $26(16.7)$ & $6(3.8)$ \\
\hline Dietary Habits & $46(29.5)$ & $71(45.5)$ & $31(19.9)$ & $8(5.1)$ \\
\hline Physical Activity & $33(21.2)$ & $59(37.8)$ & $37(23.7)$ & $27(17.3)$ \\
\hline
\end{tabular}


When respondents were asked in the in-depth interviews about counselling a patient who have not presented with the disease 6 out of 9 respondents stated that they focused more on secondary prevention rather than primary prevention.

"With that we are not very active, actually we concentrate on the secondary and not majoring on the primary because sometimes a patient will come here with probably hypertension, we are busy treating the hypertension and maybe we are not going to the nitty gritty like stress levels. We try bring the blood pressure without going into the root causes." (HCW 4)

"You know I'm not quite sure that we go out of our way really to do health promotion. It's usually the patients who initiate wanting the information. We (referring to staff) educate ourselves; we do not go out of our way to educate patients because we believe that the way we treat our patients is, "How would you like me to help you?" ... So, a lot of them will tell you this is what I have, I have pain, I have no money, I have... so usually we make a list of what they want and then we try and address those problems". (HCW)

In an effort to determine the general health promotion practices, scores were awarded based on the frequency of a healthcare worker to inquire and assess patients in order to motivate and encourage them to take up healthy life styles. The results indicated that about three in five of the health workers had average health promotion practices (Figure 6).

Figure 4: Level of practice to health promotion among study respondents

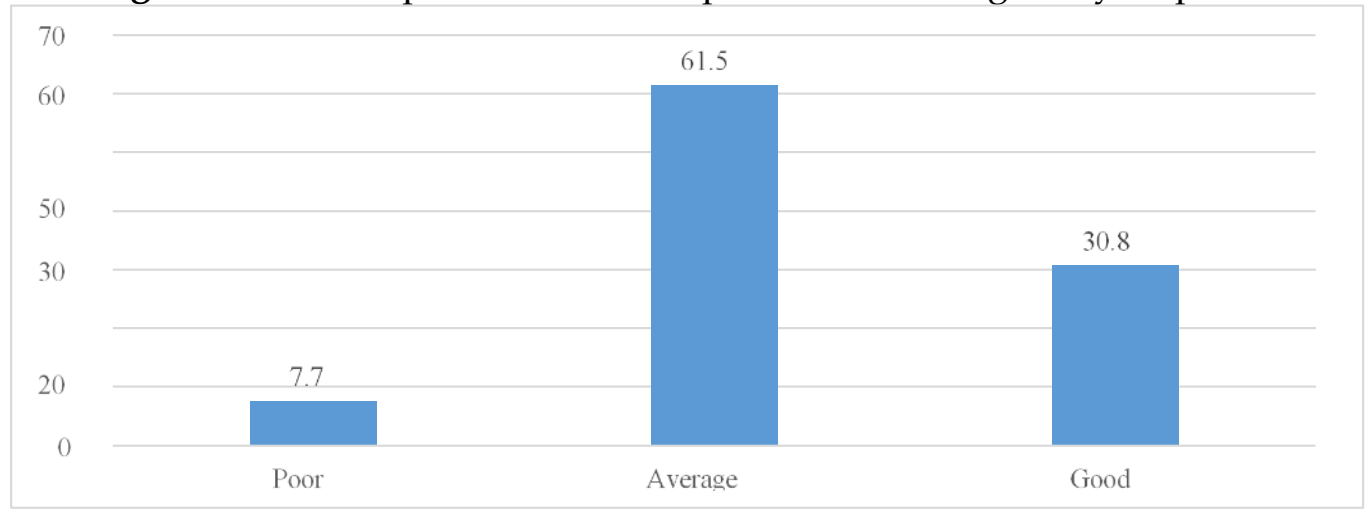

The study aimed to a on the practice of healthcare workers to arrange follow up for patients who were willing to change their behaviour or to those that were deemed at risk of developing a non-communicable disease. Upon inquiring about the patient's lifestyle practices, the study found that a majority (64\%), of the respondents took the patients through counselling on behaviour modification. However, more than half 92(59\%), of the respondents did not set up a follow up appointment to review progress of 'at risk' patient (Figure 5). When the respondents were asked in the interviews whom 
they thought was more responsible to discuss lifestyle practices, 5 out of the 9 respondents stated that they usually refer patients to the nutritionist.

"You see when we realize, let me just talk for myself, if I realize that they (patient) need to change their lifestyle by diet we refer them to the nutritionist, if we identify where the problem is, we refer". (HCW 3)

Figure 5: Action taken upon inquiring about a patient's lifestyle practice

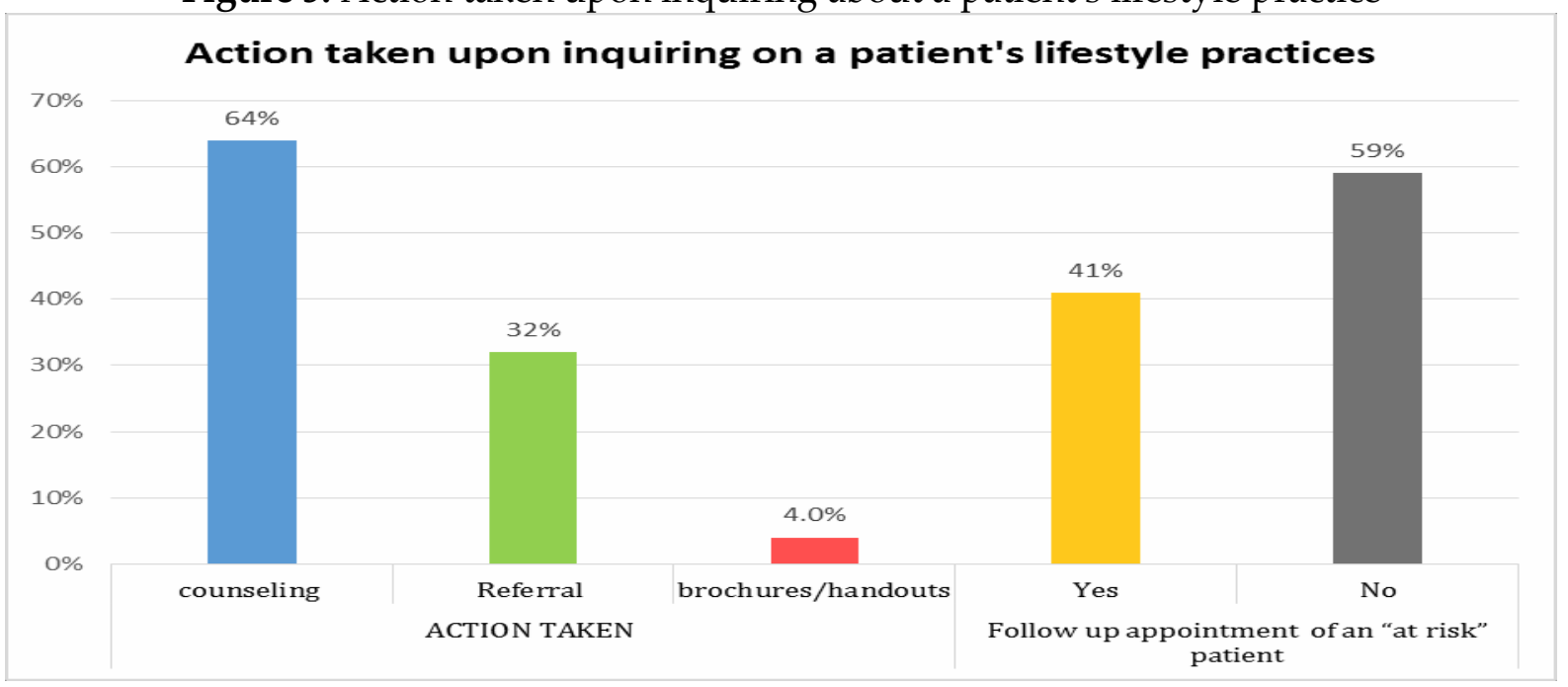

\subsection{Relationship between the Practice of Health Promotion and Socio Demographic} Factors

To determine the association between various sociodemographic characteristics and the respondents' practice of health promotion, bivariate analysis was carried out. The study showed that the respondents' gender, profession, marital status, age and years of experience were not significantly associated with the healthcare worker's practice of health promotion (Table 10).

Table 10: An Analysis of the relationship between sociodemographic characteristics and level of practice of health promotion

\begin{tabular}{|c|c|c|c|c|c|}
\hline & \multicolumn{2}{|c|}{$\begin{array}{c}\text { Health promotion } \\
\text { practice level }\end{array}$} & \multirow{2}{*}{$\begin{array}{c}\begin{array}{c}\text { Adjusted Odds } \\
\text { ratio (AOR) }\end{array} \\
\text { AOR }(95 \% \mathrm{CI}) \\
\end{array}$} & \multirow[t]{2}{*}{$\begin{array}{l}\text { Chi square } \\
\text { test }\left(\chi^{2}\right)\end{array}$} & \multirow[t]{2}{*}{$\begin{array}{c}P \\
\text { value }\end{array}$} \\
\hline & Poor/Average $\%$ & Good \% & & & \\
\hline \multicolumn{6}{|l|}{ Gender } \\
\hline Female & 35.2 & 64.8 & \multirow{2}{*}{$1.37(0.65-2.90)$} & \multirow{2}{*}{2.562} & \multirow{2}{*}{0.273} \\
\hline Male & 45.8 & 54.2 & & & \\
\hline \multicolumn{6}{|l|}{ Profession } \\
\hline Medical officer & 55.0 & 45.0 & \multirow{2}{*}{$0.36(0.13-1.02)$} & \multirow{2}{*}{5.239} & \multirow{2}{*}{0.051} \\
\hline Nurse & 36.0 & 64.0 & & & \\
\hline \multicolumn{6}{|l|}{ Marital status } \\
\hline Not yet married & 35.2 & 64.8 & $0.71(0.12-4.37)$ & \multirow{3}{*}{5.028} & \multirow{3}{*}{0.503} \\
\hline Currently married & 41.5 & 58.5 & $0.55(0.10-3.10)$ & & \\
\hline Separated/divorced & 25.0 & 75.0 & & & \\
\hline
\end{tabular}


AMONG HEALTHCARE WORKERS IN KAKAMEGA COUNTY, KENYA

\begin{tabular}{|c|c|c|c|c|c|}
\hline \multicolumn{6}{|c|}{ Age categories } \\
\hline$<=35$ & 38.9 & 61.1 & $3.08(0.22-43.03)$ & \multirow{4}{*}{9.222} & \multirow{4}{*}{0.270} \\
\hline $36-45$ & 32.5 & 67.5 & $6.00(0.56-64.18$ & & \\
\hline $46-55$ & 40.9 & 59.1 & $4.19(0.37-47.41)$ & & \\
\hline$>55$ & 75.0 & 25.0 & & & \\
\hline \multicolumn{6}{|c|}{ Years of experience } \\
\hline$<=3$ & 22.7 & 77.3 & $3.59(0.69-18.73)$ & \multirow{4}{*}{10.747} & \multirow{4}{*}{0.077} \\
\hline $4-7$ & 45.8 & 54.2 & $1.25(0.32-4.93)$ & & \\
\hline $8-10$ & 35.0 & 65.0 & $1.89(0.42-8.48)$ & & \\
\hline$>10$ & 39.4 & 60.6 & & & \\
\hline
\end{tabular}

\subsection{Relationship between level of practice and attitude to health promotion}

A statistically significant relationship was identified between level of practice and attitudes to health promotion among the study respondents. The study showed respondents with a positive attitude were 3.5 times more likely to have good health promotion practices as compared to respondents who had neutral attitudes towards health promotion $(\mathrm{OR}=3.54, \mathrm{p}=0.001)$ (Table 11).

Table 11: Relation between practice and attitudes

to health promotion among study respondents

\begin{tabular}{|c|c|c|c|c|}
\hline \multirow{2}{*}{$\begin{array}{l}\text { Attitudes to health } \\
\text { promotion }\end{array}$} & $\begin{array}{c}\text { Practice of } \\
\text { health promotion }\end{array}$ & & \multirow[t]{2}{*}{$\begin{array}{l}\text { Odds Ratio (OR) } \\
\qquad(95 \% \mathrm{CI})\end{array}$} & \multirow[t]{2}{*}{$\begin{array}{l}\mathrm{p}- \\
\text { value }\end{array}$} \\
\hline & Poor/Average & Good & & \\
\hline Neutral & 26 & 17 & \multirow{3}{*}{$3.54(1.71-7.39)$} & \multirow{3}{*}{0.001} \\
\hline Positive & 34 & 79 & & \\
\hline Total & 60 & 96 & & \\
\hline
\end{tabular}

\subsection{Influence of organizational factors on health promotion for non- communicable} diseases

To evaluate the influence of organizational factors on the attitude and practice of health promotion among healthcare workers, the study sought to assess the training levels of staff on health promotion, the HCW also rated their competency to offer counselling on lifestyle behaviour. In addition, the study aimed to reveal the available organizational structures in place which are geared towards support of health promotion practices among HCWs. The study aimed to reveal the availability of trained staff. More than half, $(58 \%)$ of the respondents stated that they had not received any formal training on health promotion methods for NCDs (Figure 6). 
Figure 6: Training on health promotion among study respondents

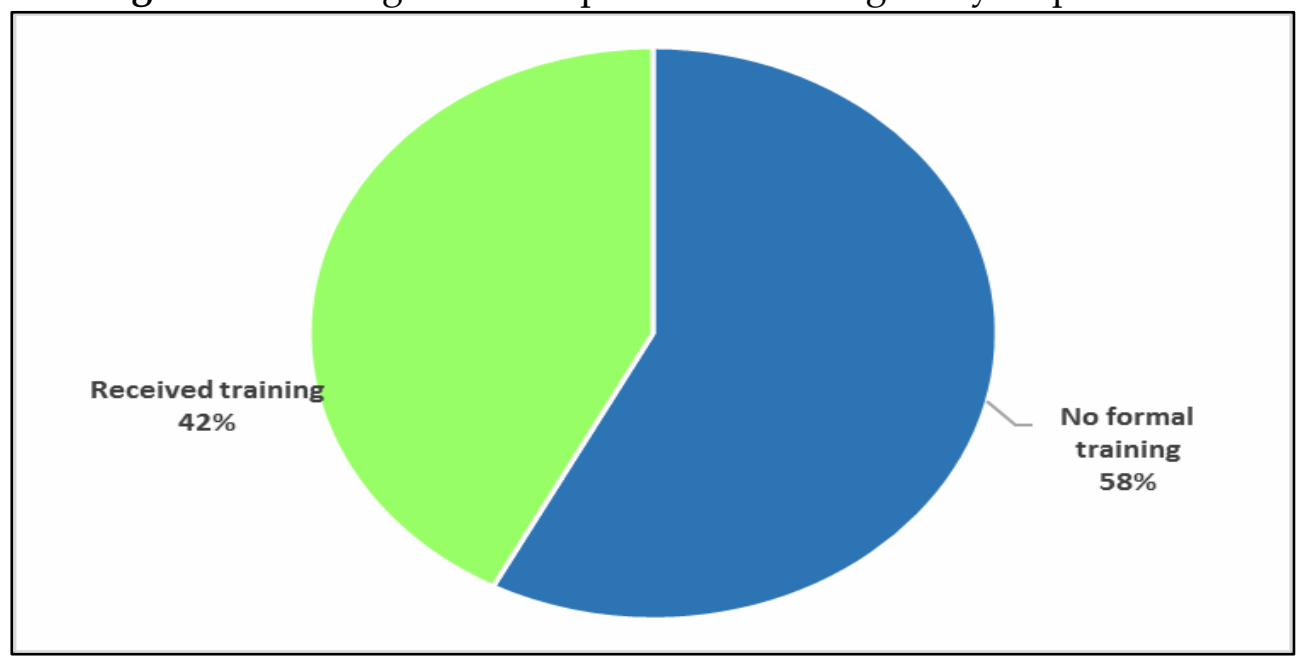

With regards to training the respondents provided multiple answers where, $42 \%$ stated that they had received formal training while about half $(56.7 \%)$ of the respondents stated that they received training during their undergraduate training (Figure 7).

Figure 7: Source of formal training on health promotion

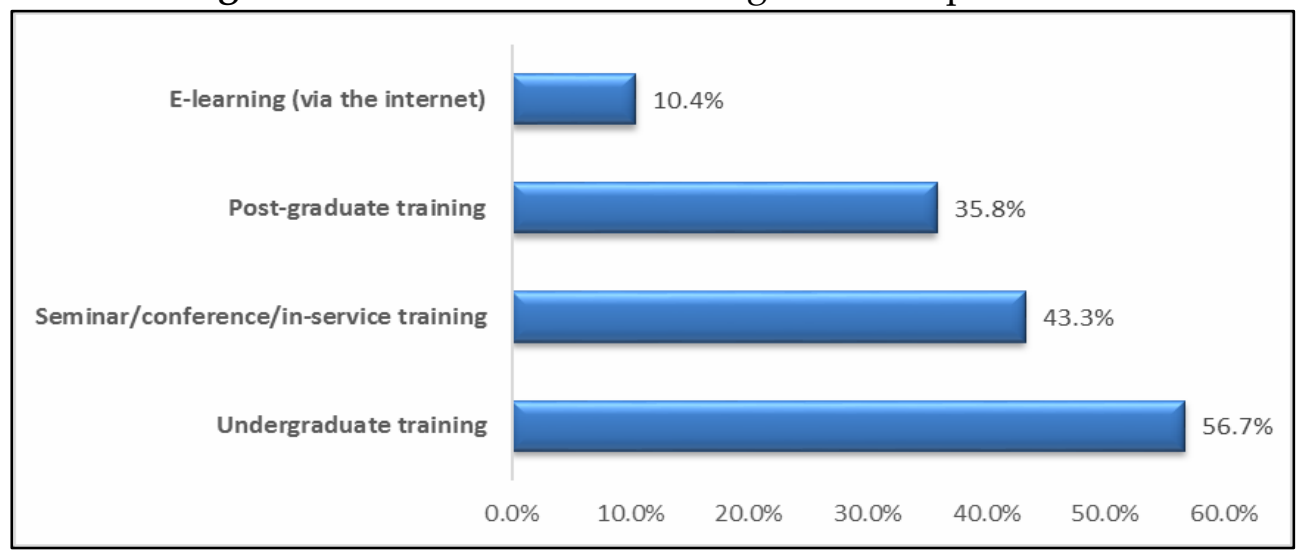

When asked if they require further training, a majority of the respondents $(73.1 \%)$ would like to receive training on health risk assessment, $71.2 \%$ on diet and nutrition, $67.3 \%$, on physical exercise and fitness, $58.3 \%$ on alcoholism and alcohol abuse counselling and $46.8 \%$ on smoking cessation techniques. However, $3.2 \%$ were not interested in all these trainings even if conveniently available. More than half of the respondents stated they were competent in providing counselling on; smoking cessation $(66 \%)$, alcoholism (64.1\%), diet and nutrition (62.2\%), and physical activity (55.1\%) (Figure 8). 
Figure 8: HCW self-reported competency on NCD risk factors

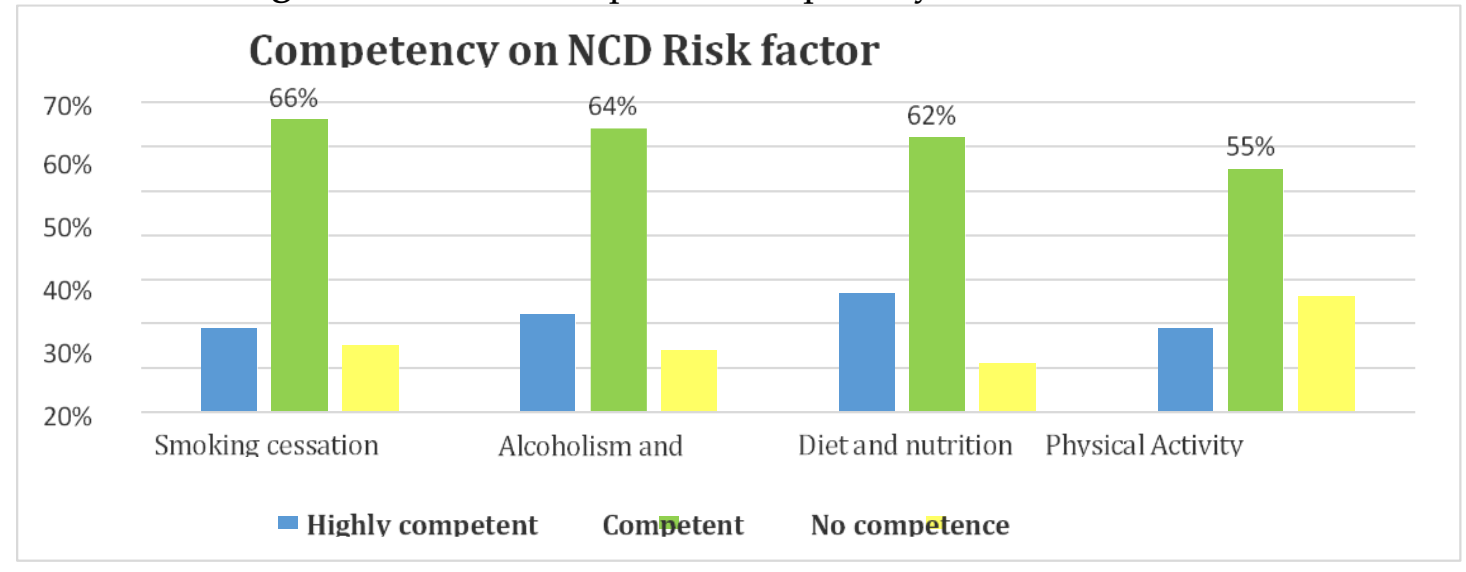

Findings from the in-depth interviews further captured the varied interpretations of what the respondents understood of the term "health promotion". Some examples include:

"Health Promotion is creation of awareness to people about health-related issues on maybe how you can prevent the occurrence of certain diseases and in case you have them how to manage them in the first level of diagnosis. So that you prevent complications of the same". (HCW 8)

"It's just these non-communicable diseases, how as in you as the health worker, how you manage them, that what I can just imagine of". (HCW 9)

\subsection{Relationship between healthcare worker's NCD competency and their inquiry of its related lifestyle risk factor}

Upon conducting a bivariate analysis, the study revealed there was significant association between health worker competence on counselling on physical activity and their inquiry of their patient's physical activity behaviour $(\chi 2=17.5, \mathrm{p}=0.007)$. (Table 12). However, counselling on alcohol use, smoking cessation, and dietary intake was found to be not statistically significant.

Table 12: Relationship between healthcare workers' competence on counselling physical activity and their inquiry practice of physical activity to patients

\begin{tabular}{|l|c|c|c|c|c|c|}
\hline \multirow{2}{*}{$\begin{array}{l}\text { Point of inquiring about } \\
\text { patient physical activity }\end{array}$} & \multicolumn{5}{|c|}{ Competence on counseling on physical activity } \\
\cline { 2 - 7 } & \multicolumn{2}{|c|}{ Highly competent } & \multicolumn{2}{|c|}{ Competent } & \multicolumn{2}{c|}{ No competence } \\
\cline { 2 - 7 } & $\mathrm{F}$ & $\%$ & $\mathrm{~F}$ & $\%$ & $\mathrm{~F}$ & $\%$ \\
\hline Never & 3 & 10 & 13 & 15.1 & 11 & 27.5 \\
\hline If the patient presents with a chronic illness & 3 & 10 & 22 & 25.6 & 12 & 30 \\
\hline To patients who are 'at risk' & 10 & 33.3 & 36 & 41.9 & 13 & 32.5 \\
\hline Every time I see a patient & 14 & 46.7 & 15 & 17.4 & 4 & 10 \\
\hline
\end{tabular}

* $\mathrm{F}=$ Frequency 


\section{Discussion}

This study aimed to describe some of the personal lifestyle practices and health- related behaviour of healthcare workers at Kakamega county referral hospital. This was important because studies have shown that they are more likely to counsel their patients about lifestyle behaviour change if they practice healthy behaviors themselves (Oberg \& Frank, 2009). The prevalence of tobacco use among healthcare workers at Kakamega county referral hospital was 3.8\%. This was relatively low compared to the national prevalence of tobacco use among Kenyan adults aged between 18-69 years, which was at 13\% (Ministry of Health, 2015b). However, smoking prevalence was slightly higher when compared to a similar study done among healthcare workers in Kiambu County, whose prevalence was $2.7 \%$ (Gichuki, 2014). The smoking prevalence may however not be indicative of the tobacco use among healthcare workers as not all healthcare professions were included in the study. Additionally, the study population consisted predominantly of women, and studies show that women are less likely to be smokers than their male counterpart (Bazargan et al., 2009). At the time of conducting the study, $30.8 \%$ of the respondents were current alcohol consumers, this was almost similar to the general population at 33\% (Ministry of Health, 2015b). A 2007 survey of Swiss doctors indicated that they consumed two times more alcohol than the general population (Sebo, Bouvier Gallacchi, Goehring, Künzi, \& Bovier, 2007). Several studies have identified high prevalence of alcohol use among HCWs and most authors attribute the high prevalence to long working schedules especially HCWs who work in inpatient wards have been shown to have tendencies of harmful alcohol consumption and higher disposable income (Montali, Campaniello, Fontechiari, Ferrari, \& Vitali, 2016; Saeys \& Cammu, 2014; Sebo et al., 2007).

The WHO recommends at least 5 servings of fruits and vegetables per day (WHO, $2013 b$ ), the respondents in the study averaged about 3 and 4 servings of fruits and vegetables, respectively. These findings are similar to a Canadian study which showed that HCWS consumed on average 4.8 servings of fruits and vegetables. (Frank \& Segura, 2009). The study found that $56 \%$ respondents were sedentary during their work period. Despite this, 56\% reported to being actively involved in exercise with brisk walking being the most common type of exercise. This study corresponds to a similar study done in South Africa where $70 \%$ of the respondents exercised occasionally with $2 \%$ exercising regularly (Montali et al., 2016). Additionally, 70\% of the healthcare workers perceived their weight to be normal with only $23 \%$ stating to be overweight. However, a study done among HCWs in South Africa, found that the majority of HCW who were overweight or obese perceived themselves as being of normal weight (Skaal \& Pengpid, 2011). Thus, proving there is a strong discrepancy between self-reporting and the actual situation. Thus, further study is required on HCWs body mass index to determine actual situation. 
A majority of the respondents in this study strongly agreed that health promotion was the responsibility of all healthcare professionals, in addition, they found it personally rewarding to discuss the lifestyle behaviour interventions with their patients'. These findings were similar to previous studies (Ampt et al., 2009; Johansson et al., 2010; Paz \& Luquis, 2014). In contradiction, the study found that a majority of the HCWs agreed that lifestyle counselling was more effective when linked to an individual presenting with chronic illness. This is consistent with findings from a German study, which showed that the decision to discuss lifestyle behaviour change was based on the specific issue with which the patient presented. In addition, the study noted that the prevention role of a doctor in a clinical setting was focused on secondary prevention rather than primary prevention (Holmberg et al., 2014). Lack of time was considered as a factor that might hinder incorporation of health promotion in general practice. It was noted that demanding work schedules restricted respondent's time to give detailed counselling. According to numerous studies, lack of time has been consistently cited as a commonly experienced obstacle for health promotion in general practice (Johansson et al., 2010; Kemppainen et al., 2013; Lambe \& Collins, 2010; McHugh et al., 2010). However, studies on smoking cessation practices among HCWs showed that brief interventions lasting less than 3 minutes could make significant impact when compared to no intervention (US Department of Health and Human Services, 2008). This finding strongly points to a need to educate HCWs on the benefits of health promotion within the hospital/ clinical settings.

The first step in the practice of health promotion is to identify and establish a record of a patient's risk factor assessment (Harris, 2008). Findings from this study indicated that less than half of the respondents inquired about tobacco use and alcohol consumption every time they saw a patient, while dietary habits and physical exercise were mainly inquired upon to 'at risk' patients. Contrary to this, the Kenya STEPwise survey report on NCDs risk factors, stated that only $8 \%$ and $10 \%$ of the general population had received lifestyle advice on tobacco and alcohol cessation respectively (Ministry of Health, 2015b). This indicates a missed opportunity in the early detection of NCDs within the general population. In addition, this study showed inadequate practice in the management of lifestyle risk factors, based on the interventions within the 5 $\mathrm{A}^{\prime} \mathrm{s}$ model. Most of the respondents performed the 'ask' and 'advice' components, while the 'assess', 'assist' and 'arrange follow up' components were mostly neglected. This corresponds to several studies which indicated that the 'assist' and 'arrange follow up' were the least practiced components (Gichuki, 2014; Harris, 2008; Paz \& Luquis, 2014). However, an Australian based study found that it might be unrealistic for HCWs to effectively carry out the 5A's approach since most HCWs view lifestyle behaviour counselling as a peripheral component of their role as focus on care and treatment a patient's specific problem. Therefore, a minimal approach of asking and arranging referral would be effective in promoting lifestyle behaviour modification. The use of minimal approach is heavily dependent on have an efficient and reliable referral system (Laws et al., 2009). Lack of training and low confidence in a HCW's ability to hinder the 
implementation of health promotion in a clinical setting (Ulla et al., 2010). This study showed that although less than half of the respondents had received formal training on health promotion at either undergraduate or post graduate level, most of the HCWs felt confident in the provision of lifestyle counselling. In addition, this study found statistical significance between healthcare worker's competence on counselling on physical activity and their inquiry of their patient's physical activity behaviour. Therefore, signifying the importance of ensuring proper training, as this will have an impact on HCWS in imparting lifestyle counselling to their patients. In addition, this study also indicated no statistical significance between HCWs health promotion practices and their sociodemographic factors such as years in practice, gender, and profession. In contrast a study done in Malta showed that the more years in clinical practice was significantly associated with HCWs confidence to provide lifestyle counselling on behaviour change (Saliba, Sammut, Vickers, \& Calleja, 2011). However, level of practice of health promotion was found to be significantly associated with the healthcare worker's attitude to health promotion this implies an interdependence of these two factors in the ensuring the practice of health promotion in a clinical setting.

This study found that not only were written policies and guidelines not available but that there was no department or personnel in the hospital organizational structure that dealt with health promotion. The respondents called for the reinstatement of the health promotion department additionally, $60 \%$ of the respondents noted that guidelines and procedures are very valuable to assist in dissemination of health promotion to patients thereby showing a willingness to undertake health promotive activities. Studies have indicated the importance of the hospital management team have a key role to ensure a clear vision and strategy is availed to HCWs and ensure commitment to implementation of health promotion activities in a clinical setting (Johansson et al., 2010; Kemppainen et al., 2013). A confounding factor in this study was that there were different variations in the interpretation of what constitutes health promotion thus can lead to unnecessary misinterpretations between disease prevention and health promotion. Studies have shown that clarity is a crucial prerequisite in successful incorporation of health promotion practices in clinical settings (Holmberg et al., 2014; Johansson et al., 2009). Thus, it's of importance to ensure adequate training of healthcare works. The study found that there was disconnect between the HCWs and management. It was noted in the in-depth interviews that, changes took long to be implemented, and that the feedback process was found wanting, as most stated the process was bureaucratic and in most instances the feedback was never obtained on a raised issue. Organizational structures are crucial in provision of clear leadership and creating an enabling environment where staff are more committed to effectively and efficiently meet organizational goals (McHugh et al., 2010). Thus, effective leadership is crucial in establishing health promotion practices. 


\section{Conclusions}

The study aimed to investigate the attitudes and practices of health promotion for noncommunicable diseases among healthcare workers. The study found that a majority of the HCWs had a positive attitude to health promotion, with more than half of the respondents strongly agreeing that it was part of their responsibility to advice patients to adopt healthy lifestyles. In addition, the study revealed a strong willingness to take up more preventive measures in tackling the rise of NCDs. Contrary to this, the study found that only a third of the respondents exhibited good practice to health promotion. In addition, most respondents stated to provide counselling to patients on lifestyle practices, yet less than half reported to provide follow up information or referral to specialist or other healthcare professionals. The study found that a positive attitude was a predictor of acceptable HP practice, therefore policy makers should put in place strategies to change the attitude of all HCWs. Based on the findings, the study recommends that the hospital management, should ensure adequate training by all staff on health promotion be reinforced through in-service training programs. The hospital management should also develop wellness programs suited for healthcare workers, to ensure personal and mental well-being of healthcare workers.

\section{Acknowledgments}

We would like to express our gratitude to health professional for their co-operation. And not to forget the extraordinary efforts of the field staff.

\section{Protection of human and animal subjects}

The authors declare that the procedures followed were in accordance with the regulations of the relevant research ethics committee and with those of the Code of Ethics of the Declaration of Helsinki.

\section{Confidentiality of data}

The authors declare that they have followed the protocols of the university on the publication of the data.

\section{Right to privacy and informed consent}

The authors have obtained the written informed consent of the patients or subjects mentioned in the article. The corresponding author is in possession of this document.

\section{Conflict of interest}

The authors declare that they have no competing interests.

\section{About the authors}

Micky Oloo is a researcher in the department of health promotion and sports sciences. Maximila Wanzala is a researcher and chair of public health department. Micky Olutende 
Oloo and Dr. Maximilla Wanzala conceived the paper, designed and performed the study. Elizabeth Mse is a senior researcher and also chair department of health promotion and sports sciences. Dr. Elizabeth Mse contributed the data collection, integrity, and analysis. Edwin Wamukoya is a senior researcher and dean school of public health Masinde Muliro university. Prof. Edwin Wamukoya conceived the paper and was the paper's peer reviewer. All authors read and approved the final manuscript.

\section{Funding}

No financial support was provided.

\section{Disclaimer}

The findings and conclusions presented in this manuscript are those of the authors and do not necessarily reflect the official position of Masinde Muliro University of Science and Technology.

\section{References}

Abdullah, A. S., Rahman, S. M., Suen, C. W., Wing, L. S., Ling, L. W., Mei, L. Y., ... Kwan, Y. H. (2006). Investigation of Hong Kong doctors' current knowledge, beliefs, attitudes, confidence and practices: implications for the treatment of tobacco dependency. Journal of the Chinese Medical Association, 69(10), 461-471. http://doi.org/10.1016/S1726-4901(09)70310-7.

Aikins, A., Unwin, N., Agyemang, C., Allotey, P., Campbell, C., \& Arhinful, D. (2010). Tackling Africa's chronic disease burden: From the local to the global. BMC Globalization and Health, 6, 1-7.

Ampt, A. J., Amoroso, C., Harris, M. F., McKenzie, S. H., Rose, V. K., \& Taggart, J. R. (2009). Attitudes, norms and controls influencing lifestyle risk factor management in general practice. BMC Family Practice, 10(1), 59. http://doi.org/10.1186/14712296-10-59.

Anderko, L., Roffenbender, J. S., Goetzel, R. Z., Howard, J., Millard, F., Wildenhaus, K., ... Novelli, W. (2012). Promoting prevention through the affordable care act: workplace wellness. Preventing Chronic Disease, 9(9), E175. http://doi.org/10.5888/pcd9.120092.

Bakhshi, S., \& While, A. E. (2014). Health professionals' alcohol-related professional practices and the relationship between their personal alcohol attitudes and behavior and professional practices: a systematic review. International Journal of Environmental Research and Public Health, 11(1), 218-48. http://doi.org/10.3390/ijerph110100218.

Bazargan, M., Makar, M., Bazargan-Hejazi, S., Ani, C., \& Wolf, K. E. (2009). Preventive, lifestyle, and personal health behaviors among physicians. Academic Psychiatry, 33(4), 289-295. http://doi.org/10.1176/appi.ap.33.4.289. 
Bleich, S. N., Bennett, W. L., Gudzune, K. A., \& Cooper, L. A. (2009). Impact of Physician BMI on Obesity Care and Beliefs. Obesity, 20(5), 999-1005. http://doi.org/10.1038/oby.2011.402.

Bleich, S. N., Bennett, W. L., Gudzune, K. A., \& Cooper, L. A. (2012). Impact of physician BMI on obesity care and beliefs. Obesity (Silver Spring, Md.), 20(5), 999-1005. http://doi.org/10.1038/oby.2011.402.

Blumenthal-Barby, J. S., \& Burroughs, H. (2012). Seeking Better Health Care Outcomes: The Ethics of Using the "Nudge." The American Journal of Bioethics, 12(2), 1-10. http://doi.org/10.1080/15265161.2011.634481

Brotons, C., Bjorkelund, C., Bulc, M., Ciurana, R., Godycki-cwirko, M., Jurgova, E., ... Vuchak, J. (2005). Prevention and health promotion in clinical practice : the views of general practitioners in Europe. Journal of Preventive Medicine, 40, 595-601. http://doi.org/10.1016/j.ypmed.2004.07.020.

Center for disease prevention. (2009). The Power of Prevention Chronic Disease... the public health challenge of the 21st century.

Chiou, S., Chiang, J., Huang, N., \& Chien, L. (2014). Health behaviors and participation in health promotion activities among hospital staff: which occupational group performs better ? BMC Health Services Research, 14, 1-7.

Coe, G., \& Beyer, D. (2014). The imperative for health promotion in universal health coverage. Global Health: Science and Practice, 2(1), 10-22. Retrieved from http://www.ghspjournal.org/content/2/1/10.full.pdf+html.

Dobe, M. (2012). Health Promotion for Prevention and Control of Non- communicable Diseases: Unfinished Agenda the Concept of Risk. Indian Journal of Public Health, 56(3), 180-186. http://doi.org/10.4103/0019-557X.104199.

Dresner, Y., Frank, E., Baevsky, T., Rotman, E., \& Vinker, S. (2010). Screening practices of Israeli doctors' and their patients. Preventive Medicine, 50(5-6), 300-303. http://doi.org/10.1016/j.ypmed.2010.02.005

Frank, E., Dresner, Y., Shani, M., \& Vinker, S. (2013). Preventive Health Practices. Canadian Medical Association Journal, 185(8), 649-654. http://doi.org/10.1503/cmaj.121028/-/DC1

Frank, E., \& Segura, C. (2009). Health practices of Canadian physicians. Canadian Family Physician Médecin de Famille Canadien, 55(8), 810-811.e7. Retrieved from http://www.pubmedcentral.nih.gov/articlerender.fcgi?artid=2726100\&tool=pmce ntrez\&rendertype $=$ abstract

Gichuki, J. W. (2014). Health care providers knowledge, attitude and practice of smoking cessation interventions in public health facilities in Kiambu county, Kenya. Unpublished Thesis, University of Nairobi.

Guo, X. H., Tian, X. Y., Pan, Y. S., Yang, X. H., Wu, S. Y., Wang, W., \& Lin, V. (2007). Managerial attitudes on the development of health promoting hospitals in Beijing. Health Promotion International, 22(3), 182-190. http://doi.org/10.1093/heapro/dam010. 
Gustafsson-wright, E., Duynhouwer, A., Gaag, J. Van Der, \& Schultsz, C. (2012). Households in Tanzania and Insurance Fund Operational. Retrieved from http://www.aiid.org/uploads/File/publications/19 USAID 2nd Study Chronic Disease Final 20121025.pdf.

Hall, V., Thomsen, R. W., Henriksen, O., \& Lohse, N. (2011). Diabetes in Sub Saharan Africa 1999-2011: epidemiology and public health implications. A systematic review. BMC Public Health, 11, 564. http://doi.org/10.1186/1471-2458-11-564.

Harris, M. (2008). The role of primary health care in preventing the onset of chronic disease, with a particular focus on the lifestyle risk factors of obesity, tobacco and alcohol. Commissioned Paper for National Preventative Health Taskforce, pp. 121. Retrieved

from http://www.health.gov.au/internet/preventativehealth/publishing.nsf/Content/0F BE203C1C547A82CA257529000231BF/\$File/commpaper-primary-hlth-careharris.pdf.

Holmberg, C., Sarganas, G., Mittring, N., Braun, V., Dini, L., Heintze, C., ... MüllerNordhorn, J. (2014). Primary prevention in general practice - views of German general practitioners: a mixed-methods study. BMC Family Practice, 15(1), 103. http://doi.org/10.1186/1471-2296-15-103.

Iwuala, S., Ayankogbe, O., Olatona, F., Olamoyegun, M., Sabir, A., \& Fasanmade, O. (2015). Obesity among health service providers in Nigeria: Danger to long term health worker retention. PanAfrican Medical Journal, 8688, 1-8. http://doi.org/10.11604/pamj.2015.22.1.5586.

Johansson, H., Stenlund, H., Lundström, L., \& Weinehall, L. (2010). Reorientation to more health promotion in health services - a study of barriers and possibilities from the perspective of health professionals. Journal of Multidisciplinary Healthcare, 3, 213-24. http://doi.org/10.2147/JMDH.S14900.

Johansson, H., Weinehall, L., \& Emmelin, M. (2009). "It depends on what you mean": a qualitative study of Swedish health professionals â€TM views on health and health promotion. BMC Health Services Research, 12(9), 1-12. http://doi.org/10.1186/1472-6963-9-191.

Johnson, A., \& Baum, F. (2001). Health promoting hospitals: A typology of different organizational approaches to health promotion. Health Promotion International, 16(3), 281-287. http://doi.org/10.1093/heapro/16.3.281.

Jonsdottir, I. H., Börjesson, M., \& Ahlborg, G. (2011). Healthcare workers' participation in a healthy-lifestyle-promotion project in western Sweden. BMC Public Health, 11(1), 448. http://doi.org/10.1186/1471-2458-11-448.

Kaduka, L. U., Kombe, Y., Kenya, E., Kuria, E., Bore, J. K., Bukania, Z. N., \& Mwangi, M. (2012). Prevalence of metabolic syndrome among an urban population in Kenya. Diabetes Care, 35(4), 887-93. http://doi.org/10.2337/dc11-0537.

Kemppainen, V., Tossavainen, K., \& Turunen, H. (2013). Nurses' roles in health promotion practice: An integrative review. Health Promotion International, 28(4), 490-501. http://doi.org/10.1093/heapro/das034. 
Kenyatta National Hospital. (2015). Kakamega county referral hospital, Quality Health Care. Retrieved March 24, 2015, from http://knh.or.ke/.

Khowaja, A., Mistry, R., Agha, A., \& Karmaliani, R. (2010). Potential benefits and perceived need for health promoting hospitals in Pakistan: A healthcare Stakeholder's perspective. Journal of the Pakistan Medical Association, 60(4), 274279.

Kingma, M. (2013). Can financial incentive influence medical practice? Human Resources Development Journal, 2(1), 1-12.

Kirigia, J. M., Sambo, H. B., Sambo, L. G., \& Barry, S. P. (2009). Economic burden of diabetes mellitus in the WHO African region. BMC International Health and Human Rights, 9, 6. http://doi.org/10.1186/1472-698X-9-6.

Klein, D., Guenther, C., \& Ross, S. (2016). Do as I say, not as I do Lifestyles and counseling practices of physician faculty at the University of Alberta. Canadian Family Physician, 62, 393-399.

Kluger, J. (2014). Women make better Doctors than Men. TIME Magazine. Retrieved from http://healthland.time.com/2013/10/17/women-make-better-doctors-than-men/.

Kreuter, M., Shobhina, C., \& Bull, F. (2009). How Does Physician Advice Influence Patient Behavior? Archives of Family Medicine, 9(May), 426-33.

Kumar, S., \& Preetha, G. (2012). Health promotion: an effective tool for global health. Indian Journal of Community Medicine, 37(1), 5-12. http://doi.org/10.4103/0970$\underline{0218.94009}$.

Lambe, B., \& Collins, C. (2010). A qualitative study of lifestyle counselling in general practice in Ireland. Family Practice, 27, 219-223. http://doi.org/10.1093/fampra/cmp086.

Law, M. R., Morris, J. K., \& Wald, N. J. (2009). Use of blood pressure lowering drugs in the prevention of cardiovascular disease: meta-analysis of 147 randomized trials in the context of expectations from prospective epidemiological studies. BMJ (Clinical Research Ed.), 338(may19_1), b1665. http://doi.org/10.1136/bmj.b1665.

Laws, R. a, Kemp, L. a, Harris, M. F., Davies, G. P., Williams, A. M., \& Eames-Brown, R. (2009). An exploration of how clinician attitudes and beliefs influence the implementation of lifestyle risk factor management in primary healthcare: a grounded theory study. Implementation Science: IS, 4, 66. http://doi.org/10.1186/1748-5908-4-66.

Laws, R. a, Kirby, S. E., Davies, G. P. P., Williams, A. M., Jayasinghe, U. W., Amoroso, C. L., \& Harris, M. F. (2008). "Should I and can I?" A mixed methods study of clinician beliefs and attitudes in the management of lifestyle risk factors in primary health care. BMC Health Services Research, 8, 44. http://doi.org/10.1186/1472-6963-8-44.

Lobelo, F., \& Quevedo, I. G. De. (2014). The Evidence in Support of Physicians and Health care Providers as Physical Activity Role Models. American Journal of Lifestyle Medicine, 1.55982761. Retrieved from http://www.ncbi.nlm.nih.gov/pmc/articles/PMC4511730/. 
McHugh, C., Robinson, A., \& Chesters, J. (2010). Health promoting health services: A review of the evidence. Health Promotion International, 25(2), 230-237. http://doi.org/10.1093/heapro/daq010.

Miller, S. K., Alpert, P. T., \& Cross, C. L. (2008). Overweight and obesity in nurses, advanced practice nurses, and nurse educators. Journal of the American Academy of Nurse Practitioners, 20(5), 259-65. http://doi.org/10.1111/j.17457599.2008.00319.x.

Ministry of Health. (2014a). Global Adult Tobacco Survey - 2014 Executive Summary. Ministry of Health. Retrieved from http://www.health.go.ke/images/gats/GATS 2014 Kenya Executive Summary.pdf.

Ministry of Health. (2014b). Kenya health sector strategic and investment plan (KHSSP) 2014-2018.

Ministry of Health. (2014c). National strategy for the prevention and control of noncommunicable disease 2015-2030. Retrieved from http://www.paho.org.

Ministry of Health. (2015a). Kenya National Health Accounts 2012/13. Retrieved from http://www.healthpolicyproject.com/pubs/523 KenyaNHA.pdf.

Ministry of Health. (2015b). Kenya STEPwise Survey for Non-communicable Diseases Risk Factors 2015 Report.

Ministry of Public Health and Sanitation. (2010). Kenya National Diabetes Strategy 20102015. Ministry of Public Health and Sanitation. Retrieved from http://diabetescommunication.org/wordpress/wp-content/uploads/2012/09/Kenya-NationalDiabetes-Strategy-2010-2015-Complete.pdf.

Montali, F., Campaniello, G., Fontechiari, S., Ferrari, M., \& Vitali, P. (2016). Alcohol consumption and physical activity among healthcare workers. Clinical Health Promotion, 6(6), 21-26.

Nugent, R. (2008). Chronic diseases: a growing problem in developing countries. Diabetesvoice, 53(May), 17-20.

Oberg, E. B., \& Frank, E. (2009). Physicians' health practices strongly influence patient health practices. The Journal of the Royal College of Physicians of Edinburgh, 39(4), 290-291. http://doi.org/10.4997/JRCPE.2009.422.Physicians.

Omar, O. A. (2007). lifestyle-related risk factors for non-communicable diseases among professionals in Nairobi. MPH Thesis Unpublished, University of Nairobi.

Parry, C. D., Patra, J., \& Rehm, J. (2011). Alcohol consumption and non-communicable diseases: epidemiology and policy implications. Addiction (Abingdon, England), 106(10), 1718-24. http://doi.org/10.1111/j.1360-0443.2011.03605.x.

Paz, H., \& Luquis, R. (2014). Attitudes About and Practices of Health Promotion and Prevention Among Primary Care Providers. Health Promotion Practice, 16(5), 745-755. http://doi.org/10.1177/1524839914561516.

Pender, N. J. (2011). Heath Promotion Model Manual. Retrieved from http://deepblue.lib.umich.edu/handle/2027.42/85350. 
Poulsen, K., Cleal, B., Clausen, T., \& Andersen, L. L. (2014). Work, diabetes and obesity: a seven-year follow-up study among Danish health care workers. PloS One, 9(7), e103425. http://doi.org/10.1371/journal.pone.0103425.

Republic of Kenya. (2012). Performance Audit Report of the Auditor-General Specialized Healthcare Delivery at Kenyatta National Hospital.

Robinson, H. M., \& Hort, K. (2012). Non-communicable diseases and health systems reform in low-and-middle-income countries. Pacific Health Dialog, 18(13), 179-90. Retrieved from http://www.ncbi.nlm.nih.gov/pubmed/23240355.

Saeys, F., \& Cammu, H. (2014). GPs' attitudes on a healthy lifestyle: A survey of GPs in Flanders. British Journal of General Practice, 64(627), e664-e669. http://doi.org/10.3399/bjgp14X681853.

Saliba, M., Sammut, M. R., Vickers, K. S., \& Calleja, N. (2011). Health behaviour counselling in primary care: general practitioner - reported rate and confidence. Malta Medical Journal, 23(1), 22-28.

Sargeant, J. (2012). Qualitative Research Part II: Participants, Analysis, and Quality Assurance. Journal of Graduate Medical Education, (March), 1-3.

Sebo, P., Bouvier Gallacchi, M., Goehring, C., Künzi, B., \& Bovier, P. (2007). Use of tobacco and alcohol by Swiss primary care physicians: a cross-sectional survey. BMC Public Health, 7, 5. http://doi.org/10.1186/1471-2458-7-5.

Shai, I., Erlich, D., Cohen, A. D., Urbach, M., Yosef, N., Levy, O., \& Shahar, D. R. (2012). The effect of personal lifestyle intervention among health care providers on their patients and clinics; the Promoting Health by Self Experience (PHASE) randomized controlled intervention trial. Journal of Preventive Medicine, 55(4), 285-291. http://doi.org/10.1016/j.ypmed.2012.08.001.

Sharma, S., Anand, T., Kishore, J., Dey, B. K., \& Ingle, G. K. (2014). Prevalence of Modifiable and Non-Modifiable Risk Factors and Lifestyle Disorders among Health Care Professionals. Astrocyte, 1(3), 178-85. http://doi.org/10.4103/23490977.157757.

Skaal, L., \& Pengpid, S. (2011). Obesity and health problems among South African healthcare workers: do healthcare workers take care of themselves? South African Family Practice, 53(6), 563-567. http://doi.org/10.1080/20786204.2011.10874153.

Spanou, C., Simpson, S. a, Hood, K., Edwards, A., Cohen, D., Rollnick, S., ... Butler, C. C. (2010). Preventing disease through opportunistic, rapid engagement by primary care teams using behaviour change counselling (PRE-EMPT): protocol for a general practice- based cluster randomised trial. BMC Family Practice, 11, 69. http://doi.org/10.1186/1471-2296-11-69.

Stead, M., Angus, K., Holme, I., Cohen, D., Tait, G., Peña, C. C., ... Costa, J. (2009). Factors influencing European GPs' engagement in smoking cessation: A multi-country literature review. British Journal of General Practice, 59(566), 682-690. http://doi.org/10.3399/bjgp09X454007

Thaker, R., Perrin, K., Daley, E., Vamos, C., \& Patel, P. (2015). Knowledge, Attitude and Health Seeking Behavior of Health Care Professionals regarding Breast and 
Cervical Cancer at Indian Medical College. NHL Journal of Medical Sciences, 4(1), 31-39.

Tyzuk, K. (2012). Physician health: A review of lifestyle behaviors and preventive health care among physicians. British Columbia Medical Journal, 54(8), 419-423.

Ulla, W., Uwe, F., Anke, N., Fischer, C., Hussein, R. J., \& Schwartz, F. W. (2010). Putting prevention into practice: qualitative study of factors that inhibit and promote preventive care by general practitioners, with a focus on elderly patients. BMC Family Practice, 11, 68. http://doi.org/10.1186/1471-2296-11-68.

US Department of Health and Human Services. (2008). Clinical Interventions for Tobacco Use and Dependence. US Department of Health and Human Services. Retrieved from http://www.ncbi.nlm.nih.gov/books/NBK63948/.

Vickers, K. S., Kircher, K. J., Smith, M. D., Petersen, L. R., \& Rasmussen, N. H. (2007). Health behavior counseling in primary care: Provider-reported rate and confidence. Family Medicine, 39(10), 730-735.

WHO. (1986). Ottawa Charter for Health Promotion. Copenhagen, Denmark.

WHO. (2005). Preventing Chronic Diseases: A Vital Investment. World Health. Retrieved from

http://scholar.google.com/scholar?hl=en\&btnG=Search\&q=intitle:Preventing+Chr onic+Diseases:+A+Vital+Investment\#3.

WHO. (2010). Global Status Report on Noncommunicable diseases 2010. Retrieved from http://whqlibdoc.who.int/publications/2011/9789240686458 eng.pdf?ua=1.

WHO. (2013a). Global action plan for the prevention and control of noncommunicable diseases 2013-2020. Retrieved from http://apps.who.int/iris/bitstream/10665/94384/1/9789241506236 eng.pdf

WHO. (2013b). Global Strategy on Diet, Physical Activity and Health. Retrieved from http://www.who.int/dietphysicalactivity/media/en/gsfs fv.pdf

WHO. (2014a). Global Status Report on Noncommunicable Diseases 2014.

WHO. (2014b). Noncommunicable diseases country profiles 2014-Kenya. Retrieved from http://www.who.int/nmh/countries/ken en.pdf?ua=1.

WHO.(2015). Physical Activity and Adults. Retrieved from http://www.who.int/dietphysicalactivity/factsheet adults/en/.

WHO-EURO. (2005). Health promotion in hospitals: Evidence and quality management. Retrieved from http://www.euro.who.int/ data/assets/pdf file/0008/99827/E86220.pdf. 
Micky Oloo Olutende, Maximilla N. Wanzala, Elizabeth Mse, Edwin Kadima Wamukoya

HEALTH PROMOTION BEHAVIOUR FOR NON-COMMUNICABLE DISEASES

AMONG HEALTHCARE WORKERS IN KAKAMEGA COUNTY, KENYA

Creative Commons licensing terms

Authors will retain the copyright of their published articles agreeing that a Creative Commons Attribution 4.0 International License (CC BY 4.0) terms will be applied to their work. Under the terms of this license, no permission is required from the author(s) or publisher for members of the community to copy, distribute, transmit or adapt the article content, providing a proper, prominent and unambiguous attribution to the authors in a manner that makes clear that the materials are being reused under permission of a Creative Commons License. Views, opinions and conclusions expressed in this research article are views, opinions and conclusions of the author(s). Open Access Publishing Group and European Journal of Physical Education and Sport Science shall not be responsible or answerable for any loss, damage or liability caused in relation to/arising out of conflict of interests, copyright violations and inappropriate or inaccurate use of any kind content related or integrated on the research work. All the published works are meeting the Open Access Publishing requirements and can be freely accessed, shared, modified, distributed and used in educational, commercial and non-commercial purposes under a Creative Commons attribution 4.0 International License (CC BY 4.0). 